Article

\title{
Digital Public Sphere and Geography: The Influence of Physical Location on Twitter's Political Conversation
}

\author{
Andreu Casero-Ripollés ${ }^{1, *}$, Josep-Lluís Micó-Sanz ${ }^{2}$ and Míriam Díez-Bosch ${ }^{2}$ \\ ${ }^{1}$ Department of Communication Sciences, Universitat Jaume I, 12071 Castelló, Spain; E-Mail: casero@uji.es \\ 2 Blanquerna School of Communication and International Relations, Universitat Ramon Llull, 08001 Barcelona, Spain; \\ E-Mails: joseplluisms@blanquerna.url.edu (J.-L.M.-S.), miriamdb@blanquerna.url.edu (M.D.-B.)
}

* Corresponding author

Submitted: 14 April 2020 | Accepted: 22 June 2020 | Published: 8 October 2020

\begin{abstract}
Social media has instituted new parameters for the political conversation in the digital public sphere. Previous research had identified several of these new phenomena: political polarisation, hate speech discourses, and fake news, among others. However, little attention has been paid to the users' geographical location, specifically to the role location plays in political discussion on social media, and to its further implications in the digital public sphere. A priori, we might think that on the digital landscape geographical restrictions no longer condition political debate, allowing increasingly diverse users to participate in, and influence, the discussion. To analyse this, machine learning techniques were used to study Twitter's political conversation about the negotiation process for the formation of the government in Spain that took place between 2015 and 2016. A big data sample of 127,3 million tweets associated with three Spanish cities (Madrid, Barcelona, and Valencia) was used. The results show that the geographical location of the users directly affects the political conversation on Twitter, despite the dissolution of the physical restrictions that the online environment favours. Demographics, cultural factors, and proximity to the centres of political power are factors conditioning the structure of digital political debate. These findings are a novel contribution to the design of more effective political campaigns and strategies, and provide a better understanding of the dynamics of the digital public sphere provided by Twitter.
\end{abstract}

\section{Keywords}

big data; democracy; digital public sphere; geography; political communication; political discussion; social media; Twitter

\section{Issue}

This article is part of the issue "The Ongoing Transformation of the Digital Public Sphere" edited by Emiliana De Blasio (LUISS University, Italy), Marianne Kneuer (Hildesheim University, Germany), Wolf J. Schünemann (Hildesheim University, Germany) and Michele Sorice (LUISS University, Italy).

(C) 2020 by the authors; licensee Cogitatio (Lisbon, Portugal). This article is licensed under a Creative Commons Attribution 4.0 International License (CC BY).

\section{Introduction}

Digital media are being configured as the dominant infrastructures in our society (Hepp, 2020). These technologies are entangled with a growing number of social activities that increasingly depend on them for their development. This causes a deep mediatization that determines how we construct our social world and that gives to the digital a central place in it (Couldry \& Hepp, 2017).

Social media in general, and Twitter in particular, is becoming an important tool in the social interactions of millions of people. Twitter's orientation towards connectivity and conversation makes it the preferred space to articulate political debates within the digital environment (Van Dijck, 2013), an aspect that confers a privileged position to this platform in the construction of the digital public sphere.

Previous research identified different facets and dynamics of the incidence of Twitter in the public sphere (Casero-Ripollés, 2018; Campos-Domínguez, 2017). Phenomena such as political polarisation, hate speech discourses, and the spreading of fake news, among oth- 
ers, have been extensively studied. Nevertheless, there remain significant and relevant issues pending analysis. Particularly pertinent among these is the role of the geographic location of users in online discussions of common public interest and civic affairs. Digital media introduce significant changes in relation to space. A priori, it should eliminate the restrictions and limits imposed by the material environment for physical reasons (Cairncross, 1997). In digital media, anyone can participate in public discussions without sharing the same geographical space. This provides the opportunity to open up and broaden the public debate to bring in more social players and other voices, producing significant transformations in the digital public sphere. The analysis of this change is highly relevant.

The aim of this article is to find out to what extent Twitter users' geographic location affects their participation and their influence in the online discussion generated by significant political events. To do this, the digital conversation concerning the negotiations to form a new government in Spain between 2015 and 2016 was studied by applying machine learning techniques. A big data sample of 127,3 million tweets linked to three cities has been used. These data lead to highly significant and innovative findings contributing to understanding the dynamics of the digital public sphere.

\section{Transformations in the Digital Public Sphere}

Digital media have introduced new parameters and conditions for the political debate in the public sphere (Castells, 2013; Fuchs, 2014). The main transformations can be identified in three particularly relevant processes: diversification, polyphony, and connectivity. These digital affordances provoke positive and negative outcomes for the dynamics of the public sphere and, ultimately, for democracy itself.

Digital media allow diversification of participants in the public discussion and increases the number of participants involved in it (Ruiz et al., 2011). Unlike mass media, social media offers the facility to produce and disseminate information and opinions to all. It makes mass selfcommunication possible as everyone is equally a sender as well as a receiver of messages (Castells, 2013). It reduces the access threshold to public debate for everyone alike. As a result, the public sphere is more diverse and is not monopolized by journalists and politicians, as in the past (Chadwick, 2017). From a purely elitist viewpoint, these two participants are central, and also indispensable, for the articulation of public opinion (Habermas, 2006). In contrast, the digital public sphere is becoming a more open and competitive landscape, which opens it up to new participants (Feenstra, Tormey, Casero-Ripollés, \& Keane, 2017). In this virtual domain, the emergence of new social movements and political activists (Lievrouw, 2011) is particularly significant. Research reveals that the media are losing their capacity for social influence, which is becoming more distributed (Casero-Ripollés, 2020).
In a context dominated by the uniformity produced by mass media, the internet generates high doses of heterogeneity, and conditions not conducive to the control of communications in the digital-based public sphere (Rasmussen, 2016).

Another substantive change process, related to the previous one, is that social media opens up the possibility that new voices can be heard in the digital public sphere (Coleman, 2017). Plurality is promoted and expanded, and, with it, public debate with the potential for more propositions to be put into circulation. Digital media allow people's free expression, encouraging freedom of speech (Shirky, 2011). This generates a polyphony of voices. This represents a significant shift towards a more democratic public sphere (Benkler, 2006). It corresponds to the Habermasian ideal that public debate needs input from citizens who give voice to society's problems (Habermas, 2006). Nevertheless, broadening the range of voices that can be heard does not prevent aggressive ones emerging - those related to hate speech and incivility, and discursive styles linked exclusively to populism (Fuchs, 2017). Moreover, this also creates a communicative abundance. From a critical perspective, the effect produced is a cacophony and dispersion of public voices (Dahlgren, 2013). Many smaller spaces coexist within the public sphere, segmented by the multiplicity of public issues in circulation. The personal dimension of digital media dilutes the concept of common public interest as a set of issues relevant to a political community (Rasmussen, 2016). The result is fragmentation and balkanization of public debate in the face of the emergence of high-choice media environments (van Aelst et al., 2017). This generates dissonances in the assortment of opinions in circulation, amplifying the effect of selective exposure to information and coincident opinions, reinforcing preconceived ideological positions and increasing political polarisation (Barnidge \& Peacock, 2019). In consequence, a more disrupted public sphere emerges (Bennett \& Pfetsch, 2018).

The digital domain also drives changes in the political information environment that has an impact on the public sphere. These changes affect the supply, regarding the quantity and quality of news and public affairs content provided, and the demand related to the amount and type of information the public wants or consumes (Esser et al., 2012). The result affects the political information that reaches people and, therefore, also their political knowledge, generating a significant impact on the public debate about democracy. The diversification of participants and information sources, coupled with the expansion of platforms on which to access news, is generating a hybrid system of political communication, in which old and new media coexist (Chadwick, 2017) and, in turn, favours the emergence of new information consumption and political participation habits (Gil de Zuñiga, Huber, \& Strauß, 2018). This process is weakening the authority of traditional media as news sources (Bennett \& Pfetsch, 2018; Carlson, 2017). The result is the ease with 
which fake news can circulate, and the rise of disinformation (Bennett \& Livingston, 2018). To this already complex and saturated news landscape, we must add the crisis in the forms of representative politics (Tormey, 2015) that is causing social apathy, distrust of representatives, and new forms of extra-representative political participation (De Blasio \& Sorice, 2019), phenomena that have a direct impact on the public sphere.

Finally, yet another transformation introduced by digital media in the public sphere is the emergence of networked publics. One of the essential characteristics of social media is its connectivity (Van Dijck, 2013). These platforms allow people to find and connect with others who have shared interests (Tufekci, 2017). This implies that the public sphere becomes a distributed discursive infrastructure (Benkler, 2006) and increases internal connectivity. Thus, networked publics are groups or constellations of people who may be in different physical locations, but nevertheless are connected to each other by who and what they are (Ito, 2008). In their formation, mobilization, connection, and disconnection, what plays a key role is the expression of sentiment and the structures of feeling that result in affective publics (Papacharissi, 2015). Emotions go on to play a key role in the articulation of networked publics and the dynamics of the public sphere as a whole. Moreover, the digital environment provokes an unbalanced participation, in that not all users are equal, nor do they have the same options to shape the public sphere (Dagoula, 2019; Fuchs, 2014).

\section{Impact of Geographical Location on the Twitter Political Conversation}

The use of social media by citizens generates large volumes of data. These frequently incorporate a significant amount of geographic information that allows us to know how citizens act in space and what the incidence of the location of users is in online interactions. These data open new opportunities to study the interrelation between geography and the digital environment (Fearnley \& Fyfe, 2018). Georeferenced user information linked to social media can also reveal a wider range of social, economic, and political phenomena (Laniado, Volkovich, Scellato, Mascolo, \& Kaltenbrunner, 2017; Shelton, Poorthuis, Graham, \& Zook, 2014; Takhteyev, Gruzd, \& Wellman, 2012). Therefore, it can be used to analyse the incidence of the geographical location of Twitter users in political conversation. In this sense, it offers new possibilities for studying how the public sphere is configured in the digital context.

The analysis of the impact of social media in relation to the role of distance has been based on two main perspectives. The first is the death of the distance's thesis (Cairncross, 1997). This technodeterminist-based approach affirms that digital communication is capable of erasing all kinds of distances and substantially varying the ways in which, until now, relations between citizens have been established. In other words, distance ceases to condition spatial interactions between citizens. Twitter, like the rest of social media, allows users to communicate and connect around mutual interests without being restricted to interact with those close to them in terms of spatial proximity. In this sense, users of this digital platform establish social links based on shared interests instead of based on shared places. For this reason, they can interact with citizens in geographically distant spaces, avoiding physical restrictions. Geographical proximity ceases to matter as people living in distant cities are as accessible as their immediate neighbours via the internet. Digital technologies can make the obstacles imposed by geography smaller and smaller. In this way, they lead to placelessness (Leamer \& Storper, 2001). This represents the end of geography, or its influence on society and on the lives of citizens, something that goes to the extreme of maintaining that the physical world is replaced by the online environment, offering new opportunities and advantages outside the old limits.

This offers new opportunities for citizen participation in the configuration of the digital public sphere. Social media, such as Twitter, allows citizens to participate in public debate regardless of where they are physically located. This allows a reduction in the costs of political participation and the generation of new opportunities to expand the public sphere to more citizens, who are no longer affected by the limitations imposed by physical distance. In this context, geography is no longer a conditioning factor for the articulation of public discussion. Thus, some researches detect a weak affinity between Twitter users and their physical proximity. The latter plays a minimal role in their interactions and conversations on this digital platform (Leetaru, Wang, Cao, Padmanabhan, \& Shook, 2013). Other studies reveal that users are much more interconnected on Twitter with users living in all parts of the United States than in space outside the Web. Everything is related to everything else, but things that are physically closer are more related in the physical environment than in the digital one (Han, Tsou, \& Clarke, 2018).

Against this position, we find the 'geography matters' thesis. This perspective affirms that, despite the potential of digital technologies to overcome distance, geographical proximity remains a key factor that determines who communicates with whom (Arthur \& Williams, 2019; Laniado et al., 2017). Despite the fact that social media offers the promise of transcending distance, connecting everyone to everyone to else, physical distance considerably limits ties and interactions in the digital space. Preexisting social ties between places and citizens play a key role on Twitter. The conversation on this platform is influenced by the spatial location of the users (Takhteyev et al., 2012). Geography continues to be a determining factor in the digital platforms and in their use by citizens.

Physical proximity continues to be important in the formation and maintenance of the social ties in social media. Citizens are less likely to establish distant online connections than nearby ones (Lengyel, Varga, Ságvári, 
Jakobi, \& Kertész, 2015). In fact, 39\% of the links between Twitter users take place in an area of less than $100 \mathrm{~km}$ (Takhteyev et al., 2012). Twitter networks in the United States are spatially constrained and follow established network patterns that are constrained by national borders and population density (Stephens \& Poorthuis, 2015). As in the physical world, the intensity and depth of interactions and ties between citizens decrease as distance increases in the digital environment.

Despite Twitter's ability to transcend physical distance, it retains strong local connectivity (Palmer, 2016). Local events attract greater attention on this platform for those who live nearby and are capable of generating a greater degree of conversation between them (Yardi \& boyd, 2010). The connections on this platform are frequently within the same city. They reflect existing "social neighbourhoods" without a digital connection. Networks on Twitter with links formed over $500 \mathrm{~km}$ are less likely to be transitive and to function as a cohesive community (Stephens \& Poorthuis, 2015). Interactions on this platform mainly replicate existing social and spatial patterns offline (Kellerman, 2016). It is impossible for Internet users to completely disconnect from the material world in which we citizens are embedded. The interactions between citizens on social media cannot do without the virtual dimension or the physical dimension. The two are interrelated and cannot be dissociated (Warf, 2013). Consequently, they are influenced in part by geographic restrictions.

Under this approach, geography and physical distance are configured as exogenous forces that condition the development of political conversation on Twitter. Therefore, it can affect the configuration of the digital public sphere. The geographic location of users, especially their material proximity, may condition their role and ability to influence public debate online. Therefore, the greater the physical distance between users, the greater the difficulties in establishing a digital interaction (Lengyel et al., 2015) and the more complex it will be to influence public discussion. Therefore, as in the offline world, only a relatively small proportion of actors are able to influence the process of public opinion formation (Casero-Ripollés, 2020; Lazarsfeld, Berelson, \& Gaudet, 1944).

Twitter has a geography that combines digital and material dimensions. Therefore, several factors affect the interactions that occur within this digital platform. First, language plays a key role in predicting links between users. Therefore, it constitutes an element that limits or expands the interactions and, therefore, the participation of more or less users in a public discussion on Twitter (Takhteyev et al., 2012). Second, regional identities also influence digital political conversation (Arthur \& Williams, 2019). Geographically anchored national and cultural backgrounds largely determine who communicates with whom and the influence in the digital environment (Kulshrestha, Kooti, Nikravesh, \& Gummadi, 2012). Third, the Twitter conversation is influenced by the ac- tivity spoken of and the spatial distribution of the users (Lansley \& Longley, 2016). Finally, the concentration of the population determines the volume of tweets produced (Longley \& Adnan, 2016). Therefore, the places with the highest accumulation of inhabitants contribute with a greater number of contents to the public sphere generated by Twitter and, therefore, can affect the digital conversation with greater force. Despite its digital materiality, Twitter is intrinsically connected to the offline world and is subject to identity, cultural, linguistic, and demographic restrictions derived from the material world.

In spite of the importance of the interrelation between digital media and geography, there is still scarce research that has studied this topic in relation to political communication. Arthur and Williams (2019) demonstrate that regional identity and sentiments, originating from the offline world, are capable of decisively determining both communication and user interactions on Twitter. Furthermore, Bastos, Mercea, and Baronchelli (2018) explore the geographical dependencies of the echo chamber communication on Twitter during the Brexit campaign. Their results reveal that echo chambers in the Leave campaign are associated with geographic proximity, while the inverse relationship occurs in the Remain campaign. Contrary to expectations, this research shows that echo chambers are not restricted to patterns linked to the digital environment but are also associated with pre-existing physical ties subject to geographic space. Thus, the influence of the geographical location of users for their communication practices within social networks is demonstrated.

According to these researches, the 'geography matters' thesis seems to be relevant in the field of political communication. The digital network and physical distances are related, reflective, and co-constructive (Stephens \& Poorthuis, 2015). And it is precisely this link that makes the study of the impact of geography on Twitter so relevant for the analysis of the transformations suffered by the public sphere in the digital environment.

Consequently, we can assume that physical proximity and geographical location of users have an impact on interactions on social media, although once inside the media, it is possible to act without spatial constraints. Nevertheless, research on this topic in the field of political communication is emerging and is still scarce. For this reason, this research addresses the following questions:

- RQ1. What is the influence of the geographical location of users living in main cities in the debate that takes place on Twitter about a highly relevant political event, such as the negotiations on the formation of the government in Spain despite the death of the distance in the digital environment?

- RQ2. How does the volume of the population of the cities affect, depending on the geographical location of the users on Twitter, their influence on 
the political conversation on this digital platform about a highly relevant event in the main cities of Spain?

- RQ3. How does proximity to the centres of political power in the cities where Twitter users are located impact their influence on the political conversation on this social media about a highly relevant event in Spain?

- RQ4. How do the cultural and linguistic aspects related to the geographical location of Twitter users affect their influence on the political conversation on this digital platform about a highly relevant event in the main cities of Spain?

\section{Methodology}

This research focuses on Twitter users' activity. The choice of this particular microblogging service is motivated by its relevance, not only as having shared content but also as being real-time. Moreover, as our object of study focuses on the field of political communication, choosing Twitter is justified as the space par excellence used by political players and journalists to communicate on, talk about, and discuss politics in the social media environment, due to the high presence of these players on this platform (Casero-Ripollés, 2018).

The methodology is based on machine learning applied to the digital behaviour of Twitter users (Kliegr, Bahník, \& Fürnkranz, 2020). Conversations on Twitter about the negotiations on the formation of the government in Spain are identified in an automated fashion. Machine learning algorithms specifically designed for this research detect these messages on Twitter, so that they then become part of the sample. Subsequently, the inclusion, or not, of tweets considered dubious was refined manually to ensure consistency and validity of the sample.

The sample focuses on the period from the day after the general elections held in Spain on December 20, 2015, until the dissolution of the Parliament and the call for new elections on May 2, 2016, triggered by the inability to form a government. This is a period of 133 days. Therefore, the sample includes messages and discussions on the negotiations to form a government. This is an event of great relevance to political life. Something that favours the ability to trigger public sphere debate.

For the purpose of carrying out the required analysis, we selected three Spanish cities: Madrid, Barcelona, and Valencia. Their inclusion is motivated by two factors. First, they are the three most-populated cities in Spain. In 2016, Madrid had 3,1 million inhabitants, Barcelona 1,6 million and Valencia 787,000. Secondly, they are the three cities with the greatest relevance and role in the Spanish political life. Their relationship with the centres of power is clearly differentiated (Villacañas, 2014). Madrid is the seat of the main political institutions (Parliament and Government) and has central preponderance in political life because of this. Barcelona is the capital of a historic nation, which, in recent years, has felt the momentum of an independence project to create their own State standing apart from Spain (MicóSanz \& Carbonell, 2017). Traditionally, it has maintained a strong rivalry with Madrid that has exacerbated this process. Finally, Valencia occupies a peripheral position with respect to the centres of political and media power and its ability to influence them is lower (Mollà, 2014).

The data has been obtained directly from the Twitter API. As a starting point, 145 accounts were selected for the analysis. They belong to representative Twitter users within the political field (leaders and parties) and media (journalists and opinion makers or political commentators). Their selection is based on three criteria: their activity on Twitter (number of tweets published), their popularity on this social media (number of followers), and their public relevance outside of the Internet (position held: media directors, well-known journalists, political leaders, members of Parliament or public officers, among others). The first two criteria are indicators of the digital relevance of users considered relevant by previous literature (Dubois \& Gaffney, 2014; Riquelme \& González-Cantergiani, 2016). The group of accounts included in the analysis meet the criteria of a strategic sample. All followers from these 145 Twitter profiles have been incorporated in the analysis, using a snowball sampling strategy. A total of 24 million accounts approximately were included.

Because of the large amount of data generated, derived from the total of 24 million accounts, for operational reasons it was decided to limit the analysis to 10,000 accounts for each of the three cities studied. Thus, population differences between the three cities are eliminated and the data is standardized for comparative analysis. To identify these 30,000 most influential users, the accounts were selected within each city according to a Pagerank calculation (Page, Brin, Motwani, \& Winograd, 1999), which determines a node's importance within a universe based on the importance of their followers. Once these accounts had been selected, the duplicate accounts occurring in more than one city were eliminated. This process resulted in the 24,389 accounts analysed. The tweet sample volume generated by these profiles during the period analysed was 127,3 million messages.

The data analysis procedure is based on the creation of 7 different groups of Twitter accounts, defined depending on the degree of influence of each one (see Table 1). A first block, formed by 3 groups, comprises of users that are only influential in their home city (groups 1 to 3 ). A second block, which also includes 3 groups, comprises accounts influential in 2 cities simultaneously (groups 4 to 6). Finally, the third block, formed by a single group (7), comprises users who are influential simultaneously in the 3 cities studied.

For the analysis of the incidence of the geographic location of users in the political conversation on Twitter, two indicators have been taken into account: the num- 
Table 1. Groups of accounts according to their degree of influence in the different sample cities.

\begin{tabular}{llr}
\hline Group & Cities & Number of Twitter accounts \\
\hline Group 1 & Barcelona & 7,517 \\
Group 2 & Madrid & 6,422 \\
Group 3 & Valencia & 5,733 \\
Group 4 & Valencia + Madrid & 2,234 \\
Group 5 & Barcelona + Madrid & 1,139 \\
Group 6 & Barcelona + Valencia & 450 \\
Group 7 & Madrid + Barcelona + Valencia & 894 \\
TOTAL & & 24,389 \\
\hline
\end{tabular}

ber of tweets published and the number of retweets. The first is an activity indicator because it measures the volume of production of information and user reviews in a particular community or city, as is our case. It involves diffusion of content and proposals within the digital public sphere and is related both to the polyphony of voices (Benkler, 2006; Coleman, 2017) and the diversity of players participating in the online discussion (Ruiz et al., 2011). The creation and dissemination of messages can potentially influence the digital conversation in the construction of the public agenda and political events framing processes. For their part, retweets perform several important functions on Twitter: a) its rebroadcasting promotes the transmission and spread of information and opinions throughout the platform; b) they enhance the public visibility of content, proposals and users; and finally c) they serve to recognise and endorse other users and opinions (boyd, Golder, \& Lotan, 2010). This is related to networked publics (Ito, 2008). The use of retweets increases the potential influence of a message or a user to third parties (Cha, Haddadi, Benevenuto, \& Gummadi, 2010). In view of this, these two variables are taken as valid indicators to measure how influence is articulated within the digital public sphere provided by Twitter.

\section{Results}

\subsection{Participation Volume in the Digital Public Sphere on Twitter}

The analysis reveals that Madrid was the city whose users generated the most tweets (19 million), compared to Barcelona (18 million) and Valencia (15 million) (see Table 2). However, Barcelona users made more retweets (62 million) compared to Madrid (55 million) and Valencia (38 million; see Table 2). This data shows that the total population is a factor that affects the number of tweets produced. Nevertheless, this variable does not decisively determine retweets production because the second city in population (Barcelona) clearly outperforms the first (Madrid). This reveals that the geographic location of most content creation does not coincide with most redistribution of content in the digital public sphere provided by Twitter.

These results show also that the profile of Valencia users is geared more towards consumption and redistribution of third-party-content-produced messages. This is consistent with the fact that Valencia is the city least connected with the centres of political and media power and with fewer possibilities to influence them. This finding reveals inequalities and gaps in the Twitter digital public sphere between different geographical locations according to their proximity to the centres of power.

The results of the retweets analysis allow us to observe that Valencia is the most closed city. That is to say, no other city has such a high number of retweets from users in the same geographical location: 8,2 million (see Table 3). On the contrary, the most permeable and open city was Madrid with 4,5 million retweets.

If we consider the retweets made by users of other cities, we can see that the population and proximity to the centres of power are factors that affect the articulation of the digital public sphere on Twitter. Thus, Madrid made 10 million retweets originating from the other two cities (Barcelona and Valencia; see Table 3), a figure that drops to 8,7 million in the case of Barcelona and 5,5 for Valencia.

\subsection{City Influence in the Digital Public Sphere on Twitter}

The analysis of the 7 groups established (see Table 1) allows us to observe the influence of the accounts in the 3 cities. The most active in terms of production of

Table 2. Overall activity (in millions) by city.

\begin{tabular}{lcr}
\hline City & Number of tweets & Number of retweets \\
\hline Madrid & 19 & 55 \\
Barcelona & 18 & 62 \\
Valencia & 15 & 38 \\
\hline
\end{tabular}


Table 3. Retweets registered based on the geographical location of users (in millions).

\begin{tabular}{lccc}
\hline & Barcelona & Madrid & Valencia \\
\hline Retweets Barcelona & 6,4 & 3,2 & 5,5 \\
Retweets Madrid & 3 & 4,5 & 7 \\
Retweets Valencia & 2 & 3,5 & 8,2 \\
\hline
\end{tabular}

messages were influential users in all three cities simultaneously (Madrid, Barcelona, and Valencia; Group 7) with 185,000 tweets per day (see Table 4). Conversely, they have the least retweets made (22,000 daily). This data shows that users who are more focused on creating content to share have a greater capacity to influence more geographical areas in political discussion on Twitter. To be influential beyond your city or community requires deploying an intense tweet production activity. Conversely, retweets do not produce such a significant effect in this sense.

From the retweet analysis, we can observe that the groups that use this feature are the ones concentrating users related to a single city (see Table 4). Moreover, the more remote the city is from the centre of power, the more the retweets generated. This shows that these users are more oriented to consumption and redistribution of views and information than the creation of new opinions in the digital public sphere on Twitter.
This data allows us to once again detect the establishment of relationship dynamics between different geographical locations. The lowest intensity of Twitter message production, indicating less connection and contact between city communities, occurs between Barcelona and Valencia, on one hand, and Madrid and Valencia, on the other (see Table 4). Similarly, the volume of users tweeting daily in group 3 in Valencia is the third smallest of the seven groups. This highlights the peripheral position of Valencia in the Twitter discussions about forming a new government in Spain.

From the analysis of the number of users that make up the seven groups (see Table 1), we can observe that the number of influential users in one of the cities is clearly superior to the rest. The sum of the percentage of users only influential in Madrid, Barcelona, and Valencia (groups 1 to 3 ) is $80.66 \%$ of the total accounts (see Figure 1). Conversely, users simultaneously influential in the three cities surveyed account for $3.67 \%$ of to-

Table 4. Daily activity in groups' accounts according to their degree of influence in different cities in the sample (in thousands).

\begin{tabular}{lrr}
\hline Group & Tweets/day & Retweets/day \\
\hline Barcelona & 125,000 & 140,000 \\
Madrid & 68,000 & 114,000 \\
Valencia & 52,000 & 149,000 \\
Barcelona + Valencia & 23,000 & 10,000 \\
Barcelona + Madrid & 135,000 & 17,000 \\
Valencia + Madrid & 29,000 & 30,000 \\
Valencia + Barcelona + Madrid & 185,000 & 22,000 \\
\hline
\end{tabular}

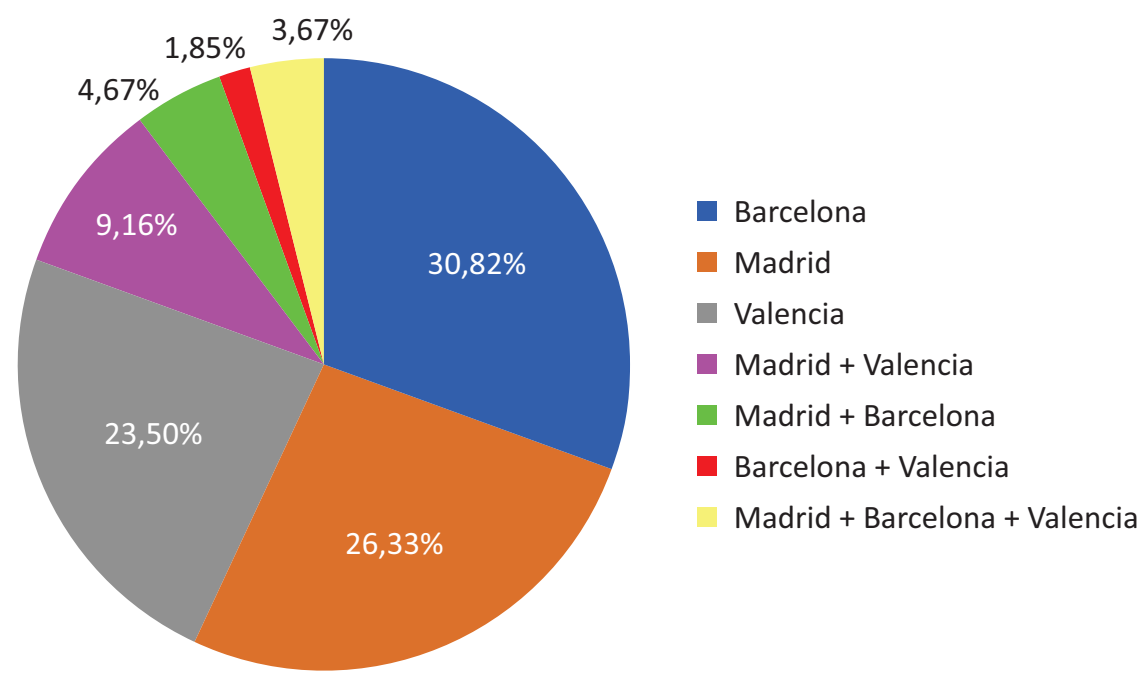

Figure 1. Percentage of users in each group according to their influence by city. 
tal accounts: 894 out of the total of 24,389 (see Table 1 ). This highlights the existence of a power-law distribution in the number of influential users in the entire digital network, that is to say, in all three cities at the same time. Therefore, only a minority are able to exert an influence on the entire digital public sphere provided by Twitter. The rest only have a limited local influence, restricted to a single city.

Finally, the data shows the low connection between accounts located in Madrid and those situated in Barcelona. Despite being the two main urban centres in Spain, only $4.67 \%$ of users are influential in both cities at the same time (see Figure 1). The historic rivalry, heightened by the independence process (Micó-Sanz \& Carbonell, 2017), and the disparity in cultural and linguistic factors may explain this lack of connection on Twitter detected between these two user communities, which, geographically speaking, are the two principal ones in the country.

\section{Conclusions}

Our research provides evidence that geographical location does indeed matter in Twitter political conversations. Our data, based on a sample of 127,3 million tweets, reveal that the physical space where users are can act to condition their activity and have influence on the digital public sphere linked to this social media platform. Although going digital dissolves barriers to public debate imposed by being in a physical offline space and allows discussions to be virtualized, our findings provide strong evidence that geography continues to have a significant impact on interactions between Twitter users regarding highly relevant political events. This research supports the 'geography matters' thesis in this digital platform (Bastos et al., 2018; Stephens \& Poorthuis, 2015; Takhteyev et al., 2012).

Another contribution of this study is the identification of some of the main factors that provoke this fact in the field of political communication. Thus, in the first place, the volume of a city's population affects the number of tweets produced in a digital political conversation, although not the number of redistributed retweets. Until now this has been demonstrated at a general level (Longley \& Adnan, 2016), but not specifically for the political arena. Population size affects the amount of information and opinions put into circulation: Users who live in cities with more inhabitants create and contribute more content in the digital debate about politics. Second, our findings suggest that proximity to physical power centres is related to the influence of users linked to those locations in the digital public sphere provided by Twitter. This is evidenced in our case with the examples of Madrid and Valencia. The first city, the seat of the institutions of the Spanish State, dominates in the number of tweets and retweets. On the other hand, Valencia, which occupies a position far from the centres of power, is configured as the community most closed in itself and is situated in a peripheral position both in the production of tweets and in the re-diffusion through retweets. This reveals the existence of inequalities and gaps in the digital public sphere between the different cities in the political conversation on Twitter.

A third relevant element is the cultural aspects, external to the digital network (Kulshrestha et al., 2012). The existence of cultural differences between cities contributes to connecting or disconnecting the users linked to them. In our case, this dynamic is evident in the case of the relationship between Madrid and Barcelona. The fact of being linked to a strongly established own culture and being involved in an independence process (Micó-Sanz \& Carbonell, 2017) leads to users of the latter city to have a low connection with users in Madrid, the country capital. According to previous research (Arthur \& Williams, 2019), our data suggest that the regional identities of users affect political conversation on Twitter.

Finally, our findings allow us to make another significant contribution. Only a small number of users $3.67 \%$ of the total) is influential in the three cities simultaneously. This responds to the parameters of a power-law distribution in which the power to condition the digital public sphere provided by Twitter is concentrated in a few hands. Consequently, the majority of users who participate in public debate online have a locally limited capacity to influence. This suggests that there are also opinion leaders (Lazarsfeld et al., 1944) in the digital domain, whose influence is related, in part, to their geographical location. The influence on this social media platform is unequal because not all users have the same possibilities to shape the public sphere (Fuchs, 2014).

In conclusion, the material space where users are located acts on the political conversation on Twitter. Geography affects how users interact in the digital public sphere, articulated by this social media platform, despite the fact that the debate takes place in a virtual environment. Far from the death of distance, our findings affirm that the physical location of users is able to condition their activity, their content and their dynamics of influence on Twitter beyond the transformations imposed by the digital environment. These findings are a novel contribution to the design of more effective electoral campaigns and political strategies and provide a better understanding of the dynamics of the digital public sphere provided by Twitter.

\section{Acknowledgments}

This article is funded by the Spanish State Research Agency-Agencia Española de Investigación (AEI) under the grant number CSO2017-88620-P.

\section{Conflict of Interests}

The authors declare no conflict of interests. 


\section{References}

Arthur, R., \& Williams, H. T. P. (2019). The human geography of Twitter: Quantifying regional identity and inter-region communication in England and Wales. PLOS ONE, 14(4). https://doi.org/10.1371/journal. pone.0214466

Barnidge, M., \& Peacock, C. (2019). A third wave of selective exposure research? The challenges posed by hyperpartisan news on social media. Media and Communication, 7(3), 4-7.

Bastos, M., Mercea, D., \& Baronchelli, A. (2018). The geographic embedding of online echo chambers: Evidence from the Brexit campaign. PLOS ONE, 13(11). https://doi.org/10.1371/journal.pone.0206841

Benkler, Y. (2006). The wealth of networks. How social production transforms markets and freedom. New Haven, CT: Yale University Press.

Bennett, W. L., \& Pfetsch, B. (2018). Rethinking political communication in a time of disrupted public spheres. Journal of Communication, 68(2), 243-253.

Bennett, W. L., \& Livingston, S. (2018). The disinformation order: Disruptive communication and the decline of democratic institutions. European Journal of Communication, 33(2), 122-139.

boyd, d., Golder, S., \& Lotan, G. (2010). Tweet, tweet, retweet: Conversational aspects of retweeting on Twitter. In Proceedings of the 2010 43rd Hawaii International Conference on System Sciences (pp. 1-10). Washington, DC: IEEE.

Cairncross, F. (1997). The death of distance: How the communications revolution will change our lives. Boston, MA: Harvard Business School Press.

Campos-Domínguez, E. (2017). Twitter y la comunicación política. El profesional de la información, 26(5), 785-793.

Carlson, M. (2017). Journalistic authority. Legitimating news in the digital era. New York, NY: Columbia University Press.

Casero-Ripollés, A. (2018). Research on political information and social media: Key points and challenges for the future. El Profesional de la Información, 27(5), 964-974.

Casero-Ripollés, A. (2020). Influence of media on the political conversation on Twitter: Activity, popularity, and authority in the digital debate in Spain. ICONO14, 18(1), 33-57.

Castells, M. (2013). Communication power. Oxford: Oxford University Press.

Cha, M., Haddadi, H., Benevenuto, F., \& Gummadi, K. P. (2010). Measuring user influence in Twitter: The million follower fallacy. In Proceedings of the Fourth International AAAl Conference on Weblogs and Social Media (pp. 10-17). Palo Alto, CA: AAAI Press.

Chadwick, A. (2017). The hybrid media system: Politics and power. Oxford: Oxford University Press.

Coleman, S. (2017). Can the internet strengthen democracy? Cambridge: Polity.
Couldry, N., \& Hepp, A. (2017). The mediated construction of reality. Cambridge: Polity.

Dagoula, C. (2019). Mapping political discussions on Twitter: Where the elites remain elites. Media and Communication, 7(1), 225-234.

Dahlgren, P. (2013). The political web: Media, participation and alternative democracy. Basingstoke: Palgrave Macmillan.

De Blasio, E., \& Sorice, M. (2019). E-democracy and digital activism: From divergent paths toward a new frame. International Journal of Communication, 13, 5715-5733.

Dubois, E., \& Gaffney, D. (2014). The multiple facets of influence: Identifying political influentials and opinion leaders on Twitter. American Behavioral Scientist, 58(10), 1260-1277.

Esser, F., de Vreese, C. H., Strömbäck, J., van Aelst, P., Aalberg, T., Stanyer, J., . . . Salgado, S. (2012). Political information opportunities in Europe: A longitudinal and comparative study of thirteen television systems. The International Journal of Press/Politics, 17(3), 247-274.

Fearnley, F., \& Fyfe, R. (2018). Twitter: An emerging source for geographical study. Geography, 103, 97-101.

Feenstra, R. A., Tormey, S., Casero-Ripollés, A., \& Keane, J. (2017). Refiguring democracy: The Spanish political laboratory. New York, NY: Routledge.

Fuchs, C. (2014). Social media and the public sphere. tripleC: Communication, Capitalism \& Critique, 12(1), 57-101.

Fuchs, C. (2017). Social media: A critical introduction. London: Sage.

Gil de Zuñiga, H., Huber, B., \& Strauß, N. (2018). Social media and democracy. El Profesional de la Información, 27(6), 1172-1180.

Habermas, J. (2006). Political communication in media society: Does democracy still enjoy an epistemic dimension? The impact of normative theory on empirical research. Communication Theory, 16(4), 411-426.

Han, S. Y., Tsou, M. H., \& Clarke, K. C. (2018). Revisiting the death of geography in the era of Big Data: The friction of distance in cyberspace and real space. International Journal of Digital Earth, 11(5), 451-469.

Hepp, A. (2020). Deep mediatization. New York, NY: Routledge.

Ito, M. (2008). Introduction. In K. Varnelis (Ed.), Networked publics (pp. 1-14). Cambridge, MA: MIT Press.

Kellerman, A. (2016). Geographic interpretations of the internet. Cham: Springer.

Kliegr, T., Bahník, Š., \& Fürnkranz, J. (2020). Advances in machine learning for the behavioral sciences. American Behavioral Scientist, 64(2), 145-175.

Kulshrestha, J., Kooti, F., Nikravesh, A., \& Gummadi, K. P. (2012). Geographic dissection of the Twitter network. In Proceedings of the Sixth International AAAl Con- 
ference on Weblogs and Social Media (pp. 202-209). Palo Alto, CA: AAAI Press.

Laniado, D., Volkovich, Y., Scellato, S., Mascolo, C., \& Kaltenbrunner, A. (2017). The Impact of geographic distance on online social interactions. Information Systems Frontiers, 20, 1203-1218. https://doi.org/ 10.1007/s10796-017-9784-9

Lansley, G., \& Longley, P. (2016). The geography of Twitter topics in London. Computers, Environment and Urban Systems, 58, 85-96.

Lazarsfeld, P. F., Berelson, B., \& Gaudet, H. (1944). The people's choice: How the voter makes up his mind in a presidential campaign. New York, NY: Duell, Sloan $\&$ Pearce.

Leamer, E. E., \& Storper, M. (2001). The economic geography of the internet age. Journal of International Business Studies, 32(4), 641-665.

Leetaru, K., Wang, S., Cao, G., Padmanabhan, A., \& Shook, E. (2013). Mapping the global Twitter heartbeat: The geography of Twitter. First Monday, 18(5/6). https:// doi.org/10.5210/fm.v18i5.4366

Lengyel, B., Varga, A., Ságvári, B., Jakobi, Á., \& Kertész, J. (2015). Geographies of an online social network. PLOS ONE, 10(9). https://doi.org/10.1371/journal. pone. 0137248

Lievrouw, L. (2011). Alternative and activist new media. Cambridge: Polity.

Longley, P., \& Adnan, M. (2016). Geo-temporal Twitter demographics. International Journal of Geographical Information Science, 30(2), 369-389.

Micó-Sanz, J. L., \& Carbonell, J. M. (2017). The Catalan political process for independence: An example of the partisan media system. American Behavioral Scientist, 61(4), 428-440.

Mollà, T. (2014). La desconnexió valenciana [The Valencian disconnection]. Valencia: Universitat de València.

Page, L., Brin, S., Motwani, R., \& Winograd, T. (1999). The PageRank citation ranking: Bringing order to the web. Stanford, CA: Stanford InfoLab.

Palmer, S. (2016). Birds of a feather: The geographic interconnection of Australian universities on Twitter. Journal of Applied Research in Higher Education, 8(1), 88-100.

Papacharissi, Z. (2015). Affective publics: Sentiment, technology, and politics. Oxford: Oxford University Press.

Rasmussen, T. (2016). The internet soapbox. Oslo: Scandinavian University Press.

Riquelme, F., \& González-Cantergiani, P. (2016). Measur- ing user influence on Twitter: A survey. Information Processing \& Management, 52(5), 949-975.

Ruiz, C., Domingo, D., Micó-Sanz, J. L., Díaz-Noci, J., Meso, K., \& Masip, P. (2011). Public sphere 2.0? The democratic qualities of citizen debates in online newspapers. The International Journal of Press/Politics, 16(4), 463-487.

Shelton, T., Poorthuis, A., Graham, M., \& Zook, M. (2014). Mapping the data shadows of Hurricane Sandy: Uncovering the sociospatial dimensions of 'big data.' Geoforum, 52, 167-179.

Shirky, C. (2011). The political power of social media: Technology, the public sphere, and political change. Foreign Affairs, 90(1), 28-41.

Stephens, M., \& Poorthuis, A. (2015). Follow thy neighbor: Connecting the social and the spatial networks on Twitter. Computers, Environment and Urban Systems, 53, 87-95. https://doi.org/10.1016/j.compenvurbsys. 2014.07.002https://doi.org/10.1016/ j.compenvurbsys.2014.07.002

Takhteyev, Y., Gruzd, A., \& Wellman, B. (2012). Geography of Twitter networks. Social Networks, 34(1), 73-81.

Tormey, S. (2015). The end of representative politics. Cambridge: Polity.

Tufekci, Z. (2017). Twitter and tear gas: The power and fragility of networked protest. New Haven, CT: Yale University Press.

van Aelst, P., Strömbäck, J., Aalberg, T., Esser, F., de Vreese, C., Matthes, J., . . . Papathanassopoulos, S. (2017). Political communication in a high-choice media environment: a challenge for democracy? Annals of the International Communication Association, 41(1), 3-27.

Van Dijck, J. (2013). The culture of connectivity: A critical history of social media. Oxford: Oxford University Press.

Villacañas, J. L. (2014). Historia del poder político en España [History of political power in Spain]. Madrid: RBA.

Warf, B. (2013). Global geographies of the internet. Dordecht: Springer.

Yardi, S., \& boyd, d. (2010). Tweeting from the town square: Measuring geographic local networks. In Proceedings of the Fourth International AAAI Conference on Weblogs and Social Media (pp. 194-201). Palo Alto, CA: AAAI Press.

\section{About the Authors}

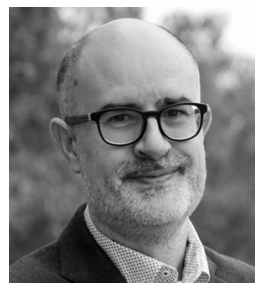

Andreu Casero-Ripollés is a Professor of Journalism and Dean of the School of Humanities and Social Sciences at the Universitat Jaume I de Castelló, Spain. Previously, he was Head of the Department of Communication Sciences and Director of Journalism Studies. He is a member of the Institut d'Estudis Catalans. He has been a visiting researcher at the Universities of Columbia, United States, and Westminster, UK, among others. He studies political communication and the transformation of journalism in the digital environment. https://orcid.org/0000-0001-6986-4163 


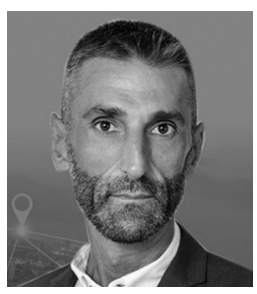

Josep-Lluís Micó-Sanz is Professor and Chair of Journalism at the Ramon Llull University (URL) in Barcelona, Spain. He is the academic and quality Vice Dean of the Blanquerna School of Communication and Internacional Relations (URL), where he directed the degree in Journalism, the Master's in Advanced Journalism Blanquerna-Grupo Godó, the Master's in Fashion Communication Blanquerna080 Barcelona Fashion, and the Master's in Sport Communication Blanquerna-FC Barcelona. He also works as a Technology Analyst in media at La Vanguardia and Radio Nacional de España-Ràdio 4. https://orcid.org/0000-0003-1191-226X

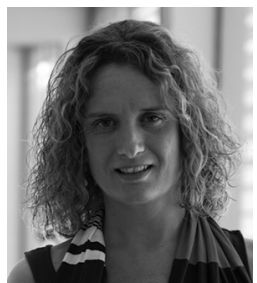

Míriam Díez-Bosch is Vice Dean of Research and International Relations at the Blanquerna School of Communication and International Relations, at Ramon Llull University, Director at the Blanquerna Observatory on Media, Religion and Culture, Director of Global Engagement at Aleteia.org, Vice President at Catalunya Religió Foundation, Member of the Global Board of the International Society for Media, Religion and Culture (Boulder, $\mathrm{CO}$ ) and Member of the Steering Committee at the Institute for Migration Studies at Comillas Pontifical University. https://orcid.org/0000-0002-3120-9443 